\title{
Effect of movement kinematics on canal transportation: reciprocation with different angles, adaptive motion, and continuous rotation
}

\author{
Ertuğrul Karataş, ${ }^{1}$ Hakan Arslan, ${ }^{1}$ Elif Kol,' ${ }^{1}$ Ibrahim Şevki Bayrakdar² \\ 'Department of Endodontics, Atatürk University, Erzurum, Turkey \\ ${ }^{2}$ Deparment of Oral Diagnosis and Radiology, Atatürk University, Erzurum, Turkey
}

\begin{abstract}
Objective: The aim of this study was to compare canal transportation in mesiobuccal root canals of extracted human mandibular molars instrumented with Twisted File Adaptive instruments with different kinematics.
\end{abstract}

Methods: A total of 60 extracted human permanent mandibular first molars with curved mesial root canals $(25<\mathrm{a}<40)$ were selected. The teeth were assigned to 5 root canal shaping groups as follows: adaptive motion, $150^{\circ}$ clockwise (CW) $-30^{\circ}$ counterclockwise (CCW), $210^{\circ} \mathrm{CW}-30^{\circ} \mathrm{CCW}, 270^{\circ} \mathrm{CW}-30^{\circ} \mathrm{CCW}$, and continuous rotation. The canals were scanned using cone-beam computed tomography (CBCT) before and after instrumentation. The degree of canal transportation at three levels and the canal centering ratio were analyzed statistically using one-way analysis of variance and Tukey's post hoc tests at a significance level of $p<0.05$.

Results: There was no significant difference in canal transportation among the groups at the three studied levels $(1,4$, and $7 \mathrm{~mm}$ from the root apex) ( $p>0.05)$. The data for the centering ratio showed that there was no significant difference among the tested groups after instrumentation in each section of the root canal $(p>0.05)$.

Conclusion: The TF Adaptive instruments produced similar canal transportation and centering ratio when used with different movement kinematics.

Keywords: Continuous rotation; kinematics; reciprocation; transportation; twisted file adaptive.

$\mathrm{C}$ leaning and shaping are the most important steps of a root canal treatment that aims removing debris and microorganisms which are responsible for endodontic pathosis from the root canals. ${ }^{[1]}$ Root canal preparation should present a flare shape from apical to coronal, maintaining the apical foramen in its original spatial relationship to the periapical tissues and to the root surface, and not changing the original canal curvature. ${ }^{[2]}$ However, in curved canals, iatrogenic errors, such as ledges, zips, perforations, and root canal transportation, might occur because there is a tendency for all preparation techniques and instruments to divert the prepared canal away from its original axis. ${ }^{[3,4]}$ Canal transportation increases the risk of blockage, perforation, and ledge creation, may weaken the root structure, and may compromise the obturation of the root canal system, resulting in a poor apical seal. ${ }^{[5]}$

Correspondence: Dr. Ertuğrul Karataş. Atatürk Üniversitesi, Diş Hekimliği Fakültesi,

Endodonti Anabilim Dalı, Erzurum, Turkey.

Tel: +90 442 - 2311746 e-mail: dtertu@windowslive.com

Submitted: June 18, 2015 Accepted: July 16, 2015 
Many root canal preparation techniques together with rotary nickel-titanium (NiTi) systems and different kinematics have been developed to overcome these problems, to maintain the original canal shape and to provide a better canal centralization. ${ }^{[6,7]}$

Recently, the Twisted File Adaptive system (TF Adaptive) (SybronEndo, Orange, CA) was introduced that uses continuous rotation when the amount of pressure based on the file is minimal. When the system engages the dentin and a load is applied, the system can change to a reciprocation mode, with specifically designed clockwise $(\mathrm{CW})$ and counterclockwise (CCW) angles, which vary from $600-0^{\circ}$ up to $370-50^{\circ}$.

According to our knowledge, an evaluation of canal transportation with different movement kinematics (reciprocating movements in various angles, adaptive motion, and continuous rotation) has not been reported. Therefore, the aim of this study was to compare the canal transportation in mesiobuccal root canals of extracted human mandibular molars instrumented with TF Adaptive instruments with different kinematics. The null hypothesis is that changing the angles of reciprocation does not change the amount of root canal transportation.

\section{Materials and methods}

A total of 60 extracted human permanent mandibular first molars with completely formed apices and curved mesial root canals were selected. Inclusion criteria included no significant calcifications and two separate mesial canals with two separate apical foramina and with severe angles of curvature $(25<\mathrm{a}<40)$. Radiographs of teeth in the buccolingual and mesiodistal directions were taken, and canal curvature was calculated by using Schneider's technique. ${ }^{[8]}$ Distal roots and crowns were removed with a high-speed bur (KG Sorensen, Barueri, SP, Brazil), and a final 15-mm working length (WL) was achieved for each tooth. After access cavities were prepared in each tooth, a size $10 \mathrm{~K}$-file (Mani Inc. Tochigi, Japan) was placed in the canal until the file was visible at the apical foramen and the working length was established $0.5 \mathrm{~mm}$ short of this length. For all teeth, the root canal width near the apex was compatible with a size $15 \mathrm{~K}$-file. This was checked by moving a 15 $\mathrm{K}$-file down to the working length. When the instrument extruded beyond the apex, the tooth was excluded from the study. The roots were randomly assigned to five experimental groups $(n=12)$.

All roots were fixed in a silicone impression material, in which each root was placed in the same position before and after instrumentation, and scanned by using the conebeam computed tomography (CBCT) scanner (NewTom FP QR-DVT 9000, Verona, Italy) operating at $110 \mathrm{kVp}$ and $15 \mathrm{~mA}$. The field of view was $17 \mathrm{~cm}$ in diameter and $13 \mathrm{~cm}$ in height.

In all groups, the root canals were instrumented using TF Adaptive instruments (SMI [20/.04], SM2 [25/.06], and SM3 $[35 / .04])$ at full WL. The canals were irrigated with $2 \mathrm{~mL} 5.25 \%$ sodium hypochlorite $(\mathrm{NaOCl})$ after each instrument change, and each instrument was used to prepare four canals.

$150^{\circ} \mathrm{CW}-30^{\circ} \mathrm{CCW}$ : In this group, instrumentation was performed using an electric motor (Satelec Endo Dual, Acteon, France) that allows the user to modify and set the reciprocating angles in the $\mathrm{CW}$ and $\mathrm{CCW}$ directions. The angles of reciprocation were set at $\mathrm{CW}=150^{\circ}$ and $\mathrm{CCW}=30^{\circ}$ for root canal preparation.

$210^{\circ} \mathrm{CW}-30^{\circ} \mathrm{CCW}$ : The angles of reciprocation were set at $210^{\circ} \mathrm{CW}$ and $30^{\circ} \mathrm{CCW}$ on the Acteon motor.

$270^{\circ} \mathrm{CW}-30^{\circ} \mathrm{CCW}$ : The angles of reciprocation were set at $270^{\circ} \mathrm{CW}$ and $30^{\circ} \mathrm{CCW}$ on the Acteon motor.

TF Adaptive: The root canals were instrumented using the Elements Motor TF Adaptive program (SybronEndo, Glendora, CA, USA).

Continuous Rotation: In this group, the root canals were instrumented using the Acteon motor at continuous rotation.

All root canals were instrumented by one operator. After the root canal instrumentation procedures, CBCT imaging of the prepared samples was repeated using the same position and parameters in order to compare preand post-images. Canal transportation and the centering ratio were analyzed at three cross-section levels that corresponded to 1, 4, and $7 \mathrm{~mm}$ distances from the apical end of the root by using the following formulas. ${ }^{[9]}$

Degree of canal transportation $=\left(\mathrm{m}_{1}-\mathrm{m}_{2}\right) \leftrightarrow\left(\mathrm{d}_{1}-\mathrm{d}_{2}\right)$

Canal centering ratio $=\left(\mathrm{m}_{1}-\mathrm{m}_{2}\right) /\left(\mathrm{d}_{1}-\mathrm{d}_{2}\right)$ or $\left(\mathrm{d}_{1}-\mathrm{d}_{2}\right) /$ $\left(\mathrm{m}_{1}-\mathrm{m}_{2}\right)$;

$\mathrm{m}_{1}$ and $\mathrm{m}_{2}$ represented the shortest mesial distances from the mesial margin of the curved root to the mesial margin of the uninstrumented and instrumented canals, respectively; $d_{1}$ and $d_{2}$ represented the shortest distal distances from the distal margin of the curved root to the distal margin of the uninstrumented and instrumented canal, respectively (Fig. 1).

According to the degree of canal transportation formula, a result of 0 indicates no canal transportation, and a result other than 0 means that transportation occurred in the canal. ${ }^{[9]}$ According to the centering ratio formula, a result of 1 indicates perfect centering. ${ }^{[10]}$

The degree of canal transportation and the canal centering ratio were analyzed statistically using one-way analysis of variance and Tukey's post hoc tests at a significance 

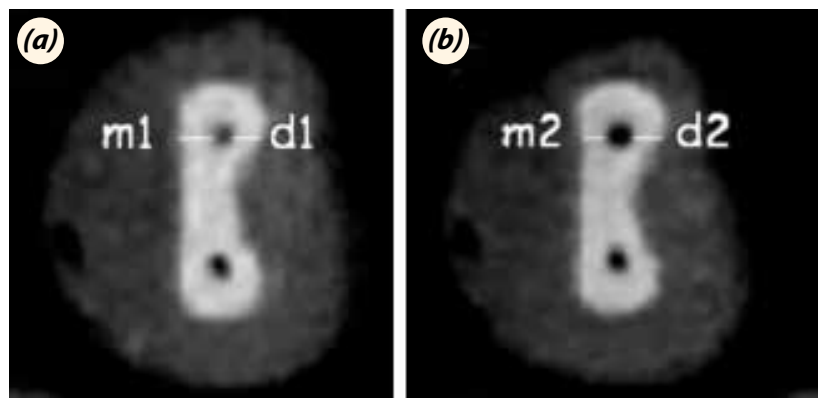

Fig. 1. Root canal transportation and centering ratio measurements (a) before instrumentation and (b) after instrumentation.

level of $\mathrm{p}<0.05$. All statistical analyses were performed with IBM SPSS Statistics 20 software (IBM SPSS Inc., Chicago, IL, USA).

\section{Results}

Table 1 shows the mean and standard deviation of the canal transportation at the 1,4 , and $7 \mathrm{~mm}$ levels for each group. There was no significant difference in canal transportation among the groups at the three studied levels ( $p>0.05)$. The data for the centering ratios showed that there was no significant difference among the tested groups after instrumentation in each section of the root canal $(p>0.05)$. Table 2 shows the mean and standard deviation of the centering ratios at the 1,4 , and $7 \mathrm{~mm}$ levels for each group.

The mean preparation times for all groups are shown in Table 2. Statistical analysis showed that there were significant differences among the groups in terms of prepara-

Table 1. Statistical Analysis of Mean Transportation Values (mm) for Tested Groups

\begin{tabular}{llllll} 
Groups & $\mathbf{n}$ & Level & Mean & Standard deviation & Preparation time (min) \\
\hline $150^{\circ} \mathrm{CW}-30^{\circ} \mathrm{CCW}$ & 12 & $1 \mathrm{~mm}$ & 0.21 & 0.13 & 2.8 \\
& 12 & $4 \mathrm{~mm}$ & 0.16 & 0.14 & 2.6 \\
$210^{\circ} \mathrm{CW}-30^{\circ} \mathrm{CCW}$ & 12 & $7 \mathrm{~mm}$ & 0.23 & 0.17 & 0.16 \\
& 12 & $1 \mathrm{~mm}$ & 0.16 & 0.25 & 2.0 \\
$270^{\circ} \mathrm{CW}-30^{\circ} \mathrm{CCW}$ & 12 & $4 \mathrm{~mm}$ & 0.14 & 0.27 & 0.14 \\
& 12 & $7 \mathrm{~mm}$ & 0.23 & 0.13 \\
Adaptive motion & 12 & $1 \mathrm{~mm}$ & 0.28 & 0.09 & 0.12 \\
& 12 & $4 \mathrm{~mm}$ & 0.13 & 0.17 \\
\hline
\end{tabular}

Table 2. Statistical Analysis of Mean Centering Ratio Values $(\mathrm{mm})$ for Tested Groups

\begin{tabular}{|c|c|c|c|c|}
\hline & n & Level & Mean & Standard Deviation \\
\hline \multirow[t]{3}{*}{$150^{\circ} \mathrm{CW}-30^{\circ} \mathrm{CCW}$} & 12 & $1 \mathrm{~mm}$ & 0.35 & 0.36 \\
\hline & 12 & $4 \mathrm{~mm}$ & 0.13 & 0.31 \\
\hline & 12 & $7 \mathrm{~mm}$ & 0.17 & 0.39 \\
\hline \multirow[t]{3}{*}{$210^{\circ} \mathrm{CW}-30^{\circ} \mathrm{CCW}$} & 12 & $1 \mathrm{~mm}$ & 0.32 & 0.42 \\
\hline & 12 & $4 \mathrm{~mm}$ & 0.14 & 0.33 \\
\hline & 12 & $7 \mathrm{~mm}$ & 0.35 & 0.25 \\
\hline \multirow[t]{3}{*}{$270^{\circ} \mathrm{CW}-30^{\circ} \mathrm{CCW}$} & 12 & $1 \mathrm{~mm}$ & 0.23 & 0.45 \\
\hline & 12 & $4 \mathrm{~mm}$ & 0.06 & 0.19 \\
\hline & 12 & $7 \mathrm{~mm}$ & 0.26 & 0.41 \\
\hline \multirow[t]{3}{*}{ Adaptive motion } & 12 & $1 \mathrm{~mm}$ & 0.24 & 0.37 \\
\hline & 12 & $4 \mathrm{~mm}$ & 0.33 & 0.49 \\
\hline & 12 & $7 \mathrm{~mm}$ & 0.15 & 0.36 \\
\hline \multirow[t]{3}{*}{ Continuous rotation } & 12 & $1 \mathrm{~mm}$ & 0.21 & 0.31 \\
\hline & 12 & $4 \mathrm{~mm}$ & 0.20 & 0.39 \\
\hline & 12 & $7 \mathrm{~mm}$ & 0.29 & 0.40 \\
\hline
\end{tabular}


tion time $(\mathrm{p}<0.05)$. The adaptive motion and continuous rotation groups were faster than the reciprocation groups $(\mathrm{p}<0.05)$. Additionally, there was a significant difference among the reciprocation groups $(\mathrm{p}<0.05)$. The $270^{\circ} \mathrm{CW}-$ $30^{\circ} \mathrm{CCW}$ group was faster than $210^{\circ} \mathrm{CW}-30^{\circ} \mathrm{CCW}$ and $150^{\circ} \mathrm{CW}-30^{\circ} \mathrm{CCW}$ groups. The adaptive motion and continuous rotation groups had similar mean preparation times $(\mathrm{p}>0.05)$.

\section{Discussion}

The present study aimed to evaluate the effect of various kinematics on canal transportation and the centering ratio in curved root canals.

Previous studies on canal transportation evaluated various file systems used in reciprocation or continuous rotation motion. ${ }^{[11-15]}$ However, these studies did not isolate the effect of kinematics on transportation because they compared different file systems. Numerous factors such as the design of the file, manufacturing method, metallurgic properties, and number of files might influence the amount and direction of apical transportation. ${ }^{[11,16-18]}$ In the present study, these variables were isolated by using TF Adaptive instruments in all groups. Morever, the root canal preparations were performed by the same operator. Thus, the operator had no effect. ${ }^{[19]}$

In the present study, there were no significant differences among the groups in terms of apical transportation and the centering ratio. This finding is in accordance with the findings of a previous study that evaluated the shaping ability of reciprocating and continuous rotation motion in curved root canals using ProTaper instruments (Dentsply Maillefer, Ballaigues, Switzerland). ${ }^{[20]}$ This previous study concluded that the application of reciprocating motion during instrumentation did not result in increased apical transportation when compared with continuous rotation motion. The cutting ability of the instrument may affect the amount of canal transportation. Adaptive motion and continuous rotation have similar cutting ability. ${ }^{[21]}$ This might be an explanation for the results of the present study.

The results of this study might have been different with less flexible instruments. Saber Sel et al. ${ }^{[22]}$ evaluated the effect of changing the reciprocation range of the WaveOne instrument (Dentsply Maillefer) (size 25, taper 0.08 ) on its fatigue life and shaping ability. They reported that decreasing the reciprocation range of WaveOne instruments resulted in increased cyclic fatigue resistance with less canal transportation. However, according to the results of the present study, changing the reciprocation range of the TF Adaptive instruments did not affect the amount of canal transportation. The conflicting results may be due to the different design and flexibility of the instruments used in the studies. More flexible files maintain the original root canal better with less canal transportation. ${ }^{[23]}$ The TF Adaptive instruments have superior flexibility due to the manufacturing process. ${ }^{[24]}$ The superior flexibility might led to similar canal transportation with different movement kinematics. The WaveOne instrument has a modified triangular cross section with radial lands at the tip and a convex triangular cross section in the middle and coronal portions of the instrument. However, the TF Adaptive instrument is characterized by a triangular cross section. Additionally, while the WaveOne technique use a large, rigid, single file with increased taper ( 0.08 taper, size 25) that directly reaches the apex, the TF Adaptive technique is a three-file technique. ${ }^{[25]} \mathrm{A}$ multiple-file system with smaller tapered instruments has an effect on the amount of canal transportation..$^{[14,15,26]}$

The study results showed reciprocation was slower than adaptive motion and continuous rotation in terms of preparation period. Reciprocation motion needed more time for one entire rotation compared with continuous rotation. ${ }^{[27]}$ Thus, the file needed more time to reach the working length. This may explain the increased preparation period in the reciprocation groups.

Cone-beam computed tomography (CBCT), which provides an accurate, reproducible, three-dimensional evaluation of root canal changes before and after instrumentation without the destruction of specimens, was used in the present study to evaluate the transportation and centering ratio values. ${ }^{[28]}$ When irregular apical preparation is performed, infected debris that can cause improper canal obturation may remain in the root canal. ${ }^{[29,30]}$ To observe this effect, apical transportation was assessed at three levels $(1,4$, and $7 \mathrm{~mm}$ from the root apex) representing the apical and middle thirds of the root canal. Wu et al. ${ }^{[31]}$ reported that the sealability of the obturating material could be negatively affected by apical transportation of more than $0.3 \mathrm{~mm}$. In the present study, no apical transportation value exceeded this limit.

\section{Conclusion}

Within the limitations of this study, the TF Adaptive instruments produce similar canal transportation and centering ratios when used with different movement kinematics (reciprocation, continuous rotation, and adaptive motion). Further studies should be conducted to confirm the results.

\section{Acknowledgement}

The authors deny any financial affiliations related to this study or its sponsors. There is no any conflict of interest. This study has been conducted in full accordance with the 
World Medical Association Declaration of Helsinki.

Conflics of Interest: No conflicts declared.

\section{References}

1. Yamamura B, Cox TC, Heddaya B, Flake NM, Johnson JD, Paranjpe A. Comparing canal transportation and centering ability of endosequence and vortex rotary files by using micro-computed tomography. J Endod 2012;38:1121-5.

2. Schilder H. Cleaning and shaping the root canal. Dent Clin North Am 1974;18:269-96.

3. Abou-Rass M, Frank AL, Glick DH. The anticurvature filing method to prepare the curved root canal. J Am Dent Assoc 1980;101:792-4.

4. Weine FS, Kelly RF, Lio PJ. The effect of preparation procedures on original canal shape and on apical foramen shape. J Endod 1975;1:255-62.

5. Franco V, Fabiani C, Taschieri S, Malentacca A, Bortolin M, Del Fabbro M. Investigation on the shaping ability of nickel-titanium files when used with a reciprocating motion. J Endod 2011;37:1398-401.

6. Schäfer E, Florek H. Efficiency of rotary nickel-titanium $\mathrm{K} 3$ instruments compared with stainless steel hand $\mathrm{K}$ Flexofile. Part 1. Shaping ability in simulated curved canals. Int Endod J 2003;36:199-207.

7. Weine FS. The use of non-ISO-tapered instruments for canal flaring. Compend Contin Educ Dent 1996;17:6516, 658-60, 662-4.

8. Schneider SW. A comparison of canal preparations in straight and curved root canals. Oral Surg Oral Med Oral Pathol 1971;32:271-5.

9. Gambill JM, Alder M, del Rio CE. Comparison of nickeltitanium and stainless steel hand-file instrumentation using computed tomography. J Endod 1996;22:369-75.

10. Paqué F, Laib A, Gautschi H, Zehnder M. Hard-tissue debris accumulation analysis by high-resolution computed tomography scans. J Endod 2009;35:1044-7.

11. Capar ID, Ertas H, Ok E, Arslan H, Ertas ET. Comparative study of different novel nickel-titanium rotary systems for root canal preparation in severely curved root canals. J Endod 2014;40:852-6.

12. Junaid A, Freire LG, da Silveira Bueno CE, Mello I, Cunha RS. Influence of single-file endodontics on apical transportation in curved root canals: an ex vivo micro-computed tomographic study. J Endod 2014;40:717-20.

13. Gergi R, Arbab-Chirani R, Osta N, Naaman A. Microcomputed tomographic evaluation of canal transportation instrumented by different kinematics rotary nickel-titanium instruments. J Endod 2014;40:1223-7.

14. Gergi R, Osta N, Bourbouze G, Zgheib C, Arbab-Chirani $R$, Naaman A. Effects of three nickel titanium instrument systems on root canal geometry assessed by micro-comput- ed tomography. Int Endod J 2015;48:162-70.

15. Marzouk AM, Ghoneim AG. Computed tomographic evaluation of canal shape instrumented by different kinematics rotary nickel-titanium systems. J Endod 2013;39:906-9.

16. Freire LG, Gavini G, Branco-Barletta F, Sanches-Cunha R, dos Santos M. Microscopic computerized tomographic evaluation of root canal transportation prepared with twisted or ground nickel-titanium rotary instruments. Oral Surg Oral Med Oral Pathol Oral Radiol Endod 2011;112:143-8.

17. Ersev H, Yilmaz B, Ciftçioğlu E, Ozkarsli SF. A comparison of the shaping effects of 5 nickel-titanium rotary instruments in simulated S-shaped canals. Oral Surg Oral Med Oral Pathol Oral Radiol Endod 2010;109:86-93.

18. Shen Y, Zhou HM, Zheng YF, Campbell L, Peng B, Haapasalo M. Metallurgical characterization of controlled memory wire nickel-titanium rotary instruments. J Endod 2011;37:1566-71.

19. Zhao D, Shen Y, Peng B, Haapasalo M. Micro-computed tomography evaluation of the preparation of mesiobuccal root canals in maxillary first molars with Hyflex CM, Twisted Files, and K3 instruments. J Endod 2013;39:3858.

20. You SY, Kim HC, Bae KS, Baek SH, Kum KY, Lee W. Shaping ability of reciprocating motion in curved root canals: a comparative study with micro-computed tomography* J Endod 2011;37:1296-300.

21. Gambarini G, Giansiracusa Rubini A, Sannino G, Di Giorgio G, Piasecki L, Al-Sudani D, et al. Erratum to: Cutting efficiency of nickel-titanium rotary and reciprocating instruments after prolonged use. Odontology 2015. [Epub ahead of print]

22. Saber Sel D, Abu El Sadat SM. Effect of altering the reciprocation range on the fatigue life and the shaping ability of WaveOne nickel-titanium instruments. J Endod 2013;39:685-8.

23. Madureira RG, Forner Navarro L, Llena MC, Costa M. Shaping ability of nickel-titanium rotary instruments in simulated S-shaped root canals. Oral Surg Oral Med Oral Pathol Oral Radiol Endod 2010;109:136-44.

24. Gambarini G, Gerosa R, De Luca M, Garala M, Testarelli L. Mechanical properties of a new and improved nickeltitanium alloy for endodontic use: an evaluation of file flexibility. Oral Surg Oral Med Oral Pathol Oral Radiol Endod 2008;105:798-800.

25. Gambarini G, Testarelli L, De Luca M, Milana V, Plotino G, Grande NM, et al. The influence of three different instrumentation techniques on the incidence of postoperative pain after endodontic treatment. Ann Stomatol (Roma) 2013;4:152-5.

26. Gergi R, Rjeily JA, Sader J, Naaman A. Comparison of canal transportation and centering ability of twisted files, Pathfile-ProTaper system, and stainless steel hand K-files 
by using computed tomography. J Endod 2010;36:904-7. 27. Gambarini G, Rubini AG, Al Sudani D, Gergi R, Culla A, De Angelis F, et al. Influence of different angles of reciprocation on the cyclic fatigue of nickel-titanium endodontic instruments. J Endod 2012;38:1408-11.

28. Hashem AA, Ghoneim AG, Lutfy RA, Foda MY, Omar GA. Geometric analysis of root canals prepared by four rotary NiTi shaping systems. J Endod 2012;38:996-1000.
29. Bürklein S, Schafer, E. Critical evaluation of root canal transportation by instrumentation. Endodontic Topics 2013;29:110-24.

30. Metzger Z, Solomonov, M, Kfir, A. The role of mechanical instrumentation in the cleaning of root canals. Endodontic Topics 2013;29:87-109.

31. Wu MK, Fan B, Wesselink PR. Leakage along apical root fillings in curved root canals. Part I: effects of apical trans- 